\title{
GC-MS/Olfactometric characterisation and aroma extraction dilution analysis of aroma active compounds in Polygonum minus essential oil
}

\author{
Nor Azizun Rusdi, Hoe-Han Goh, Syarul Nataqain Baharum* \\ Metabolomics Research Laboratory, Institute of Systems Biology (INBIOSIS), Universiti Kebangsaan Malaysia, \\ 43600 Bangi, Selangor, Malaysia
}

\section{*Corresponding author: nataqain@ukm.edu.my}

\begin{abstract}
Polygonum minus Huds. is an aromatic plant with potential anti-inflammatory, antiulcer and diuretic properties. Although the volatile compounds from the essential oil of $P$. minus have been extensively studied, knowledge of the aroma-active compounds is still incomplete. Hence, the aim of this study is to investigate and to characterise the aroma-active compounds that contribute to the potent odour of $P$. minus. Essential oil was extracted from the leaves of kesum ( $P$. minus) using hydrodistillation and was analysed by gas chromatography-mass spectrometry (GC-MS) to identify the volatile constituents. The important aroma-active compounds were further analysed by GC-MS/Olfactometry (GC-MS/O) and aroma extraction dilution analysis (AEDA). The GC-MS analysis using Kováts retention indices detected 39 volatile compounds in the essential oil. Aldehydes represented the major class of compounds, encompassing $75.43 \%$ of the total peak area, followed by sesquiterpenes $(13.19 \%)$, alcohols $(8.07 \%)$ and organic acids $(0.83 \%)$. The dominant components of the kesum essential oil were dodecanal $(54.25 \%)$ and decanal $(18.27 \%)$ in the aldehyde group. The sesquiterpenes that were detected include $\beta$-farnesene $(1.74 \%), \alpha$-caryophyllene $(1.72 \%)$, $\beta$-caryophyllene oxide $(1.51 \%)$ and $\beta$ selinene (1.36\%). In this study, GC-MS/O and AEDA analysis identified dodecanal, decanal, farnesol, 1-nonanal and $\alpha$-bergamotene as the main contributors to the characteristic fragrance of this plant. This is the first olfactometric study on the essential oil of $P$. minus, and it is important for our understanding of the biosynthesis of volatile compounds in this medicinal herb. Moreover, the characterisation of aromatic compounds that contributed to the potent odour of $P$. minus can be further applied in the flavour and fragrance industries.
\end{abstract}

Keywords: AEDA, aldehydes, essential oil, GC-MS/O, Polygonum minus Huds.

Abbreviations: AEDA_Aroma extraction dilution analysis; FD_dilution factor; GC-FID_Gas chromatography-flame ion detector; GC-MS/O_Gas chromatography-mass spectrometry/olfactometry; GC-O_Gas chromatography-olfactory; GCxGC-TOF-MS_Gas chromatography $\mathrm{x}$ gas chromatography-time-of-flight mass spectrometry; RA_Relative abundance; RI_retention indices.

\section{Introduction}

Polygonum minus Huds. (syn. Persicaria minor), locally known as 'kesum', is an herbaceous plant from the Polygonaceae family. This aromatic plant originated in Southeast Asian countries, namely Malaysia, Thailand, Vietnam and Indonesia (Bunawan et al., 2011). It grows in moist areas near river banks, ditches and lakes. P. minus produces sweet and pleasant aroma and is commonly used as flavouring in Malaysian cuisine. It has been recognised and listed as an important essential oil-producing crop in the Malaysian National Herbal Product Blueprint (Wan Hasan, 2007). Traditionally, it has been widely used in the treatment of digestive problems and to reduce dandruff (Zakaria and Mohd, 2010).

Our previous study reported that $P$. minus contains a high level of flavonoid and phenolic compounds as antioxidants (Ahmad et al., 2014). Furthermore, moderate levels of anticancer and antibacterial activities were demonstrated by P. minus crude extracts (Ahmad et al., 2014). Other bioactivities include antiulcer, anti-inflammatory (George et al., 2014) and anti-ageing (Haris et al., 2014). Hence, $P$. minus plants have great potential as natural products in aromatherapy and in the pharmaceutical industry. The aroma and flavour of kesum are mainly contributed by the essential oils produced in the leaf glandular trichomes. The essential oil of kesum obtained by hydrodistillation is a pale yellow liquid with an intense, pungent, orange-like, fresh odour. A previous report on the extraction of kesum oil by hydrodistillation identified 42 compounds by GC-MS, GCxGC-TOF-MS and GC-FID (Baharum et al., 2010). In all, more than 70 volatile compounds in the groups of aldehydes, terpenes, alcohols and esters were found in the $P$. minus essential oil. However, only a small fraction of the volatiles contribute to the characteristic aroma. GC-olfactometry (GCO) makes it possible to classify volatiles into odour-active and non-odour-active compounds relative to their concentrations in the sample.

Traditionally, the analysis and measurement of odours are performed separately using a GC-O apparatus (Acree, 1997). This technique allows the identification and detection of distinct odours in a complex mixture of hundreds of compounds (Lo et al., 2008). The GC-O apparatus combines olfactometry or use of the human nose as a selector to detect the aroma-active compounds in various essential oils (Delahunty et al., 2006). The GC-O technique was applied to determine the seasonal variation in the aromatic profiles of Thymus hyemalis and Spanish T. vulgaris essential oils 
(Goodner et al., 2006). Miyazawa et al. (2013) reported the characterisation of essential oils from Scutellaria laeteviolacea, which is an important traditional Chinese medicine. Furthermore, GC-O in combination with a mass spectrometer (GC-MS/O) enables compound identification of odourants through human sensory perception. By separating the individual components of odorous mixtures and combining the human nose perception with simultaneous mass spectrometry, odourants within very complex mixtures can be identified (Brattoli et al., 2013). The development of an MS-library enables a more reliable GC-MS/O analysis for odour quality determination.

The combination of GC-MS/O and aroma extraction dilution analysis (AEDA) provides a more in depth analysis of aroma-active compounds. In the case of AEDA, the result is expressed as a flavour dilution (FD) factor, which is a ratio of the odourant concentration in the initial extract to its concentration in the most diluted extract of which the odour is still detectable by GC-O. An extract is diluted as a series of $1: 2$ or 1:3 dilutions, and each dilution is sniffed until no significant odour is detected (Kang and Baek, 2014; Van Ruth, 2001). The aim of this study is to use GC-MS/O as a technique to profile and identify chemical compounds that contribute to the potent aroma of kesum. In this study, our main focus is on the application of AEDA to characterise aroma-active compounds in P. minus. To our knowledge, this is the first attempt to profile the aroma-active compounds of this tropical, herbaceous plant. The standard aroma profile obtained will help in understanding the characteristic fragrance of $P$. minus.

\section{Results and Discussion}

\section{Identification and quantification of the volatile components in P. minus}

P. minus yellowish essential oil was obtained at $0.475 \%$ yield. GC-MS analysis of the essential oil led to the identification of 39 volatile compounds, which were grouped and categorised according to their functional groups, namely, aldehydes, alcohols, terpenoids (monoterpenes, sesquiterpenes) and acids (Table 1 and Fig. 1).

The major volatiles were dodecanal $(54.25 \%)$, followed by decanal $(18.72 \%)$, geraniol (1.82\%), $\beta$-farnesene $(1.73 \%), \alpha-$ caryophyllene $(1.72 \%), \quad 1$-dodecanol $(1.63 \%)$ and $\beta$ caryophyllene oxide $(1.51 \%)$. Aldehydes $(75.43 \%)$ constitute the most abundant proportion of the essential oil. Meanwhile, the highest number of compounds was identified in the terpenoid group $(13.19 \%)$. $\beta$-farnesene, $\alpha$-caryophyllene, $\beta$ caryophyllene oxide, $\beta$-selinene, $\alpha$-bergamotene, germacrene $\mathrm{D}$ and $\delta$-cadinene were the major $(\mathrm{RA}>1 \%$ ) sesquiterpenes detected. Thirteen alcohol compounds were identified and contributed to only $8.07 \%$ of the total composition. Geraniol, 1-dodecanol, $\alpha$-bisabolol and nerolidol were the four most abundant alcohols found. Other minor compounds included one monoterpene (bornyl acetate), which accounted for $0.91 \%$, and two organic acids, which were found in low amounts.

Dodecanal (54.25\%) was the most abundant component in the essential oil, in agreement with the findings of Ahmad et al. (2014), who identified decanal and dodecanal as the dominant components that contributed to the pungent flavour of $P$. minus. Ahmad et al. (2014) found that 77 metabolites from three different organs of $P$. minus and aliphatic compounds contribute significantly to the aroma and flavour of this plant. A total of 48 and 42 compounds were identified from the essential oil of $P$. minus by $\mathrm{GC} \times \mathrm{GC}-\mathrm{MS}-\mathrm{TOF}$ and
GC-MS, respectively (Baharum et al., 2010). The essential oil of Polygonum hydropiper was reported to contain $\beta$ farnesene $(44.1 \%)$, phytol $(10.8 \%), \alpha$-caryophyllene $(9.3 \%)$ and nerolidol (6.9\%) (Jiang, 2005).

It is possible that the differences in the volatile composition of $P$. minus samples could be related to the extraction and analysis methods. Ahmad et al. (2014) identified more compounds, especially in monoterpenes, aliphatics and organic groups, using solid-phase microextraction (SPME) compared to our hydrodistillation approach. Starkenmann et al. (2006) studied the volatile constituents of this herb oil extracted by hydrodistillation and reported that aldehydes, such as dodecanal, decanal, (Z)-3-hexanal, (E)-2-hexanal and (Z)-3-hexen-1-ol, were the major compounds. He also successfully profiled polygodial, a 1,4-dialdehyde derived from the drimane terpenoids of Persicaria hydropiper (L.) and in Persicaria odorata (Lour.). Furthermore, all the essential oils and crude extracts of $P$. minus showed a similar trend, containing a complex mixture of aldehydes, sesquiterpenes, monoterpenes, functionalised hydrocarbons, acids and ester.

Hunter et al. (1996) applied steam distillation to Australian Persicaria odorata essential oil and identified 17 components, with dodecanal (44.1\%) and decanal (27.7\%) as the major compounds, and sesquiterpenes ( $\alpha$-humulene, $\beta$ caryophyllene) accounted for approximately $15 \%$ of the essential oil. Five new sesquiterpenes, alloaromadendrene, $\alpha$ bisabolene, valencene, $\delta$-cadinene and farnesol, were detected in small quantities but were not found in the previous study (Baharum et al., 2010).

The essential oils of herbal and medicinal plants contain a significant variation of compounds due to several factors, such as physiology (tissue type and amount used), environmental conditions (climate, pollution, diseases, pests and edaphic factors), genetic factors and storage (Figueiredo et al., 2008). Bondia-Pons (2014) suggested that geographical origin is one of the most important parameters because differences in climate, soil, and cultivation methods could cause differences in the chemical composition of the plants.

\section{Aroma extraction dilution analysis}

Potent odourants were analysed using AEDA for the determination of the flavour dilution (FD) factors. The results of the olfactometric analysis are summarised in Table 2, and the aromagram obtained from AEDA analysis is shown in Fig. 2. A total of eighteen odour-active compounds, which comprised five aldehydes, ten sesquiterpenes, one monoterpene and one fatty alcohol, were identified in $P$. minus essential oils. The FD factors of the perceived compounds were within the range of $\geq 16-1024$. Based on the GC-MS/O analysis, we discovered that the most potent aroma-active compounds were long-chain aliphatic aldehydes, namely, decanal and dodecanal, with the highest FD value of 1024 . The first has a green, citrus-like fragrance, and the latter is a pungent oil. Furthermore, $\alpha$-bergamotene was identified as the most potent sesquiterpene in the characteristic odour of $P$. minus.

Aldehydes were characterised and described by most panellists as green and pungent, with orange peel-like citrus notes (Kesen et al., 2014). Meanwhile, according to Brunschwig et al. (2012), the aldehyde compounds in Tahitian vanilla essential oil were classified as having fatty, fruity and chocolate notes. The next most important aromaactive aldehydes with respect to the FD factor were 1nonanal (citrus, green) and undecanal (pungent, citrus). The FD factor values of these compounds were 512 and 256 . The 
Table 1. Compounds identified from P. minus essential oil grouped according to different chemical classes.

\begin{tabular}{|c|c|c|c|c|c|}
\hline Peak no. & Compound $^{\mathrm{a}}$ & $\mathrm{RI}^{\mathrm{b}}$ & Chemical formula & $\mathrm{RA}^{\mathrm{c}}(\%)$ & Identification method $^{\mathrm{d}}$ \\
\hline & Aldehyde & & & & \\
\hline 1 & $\overline{\text { Decanal }}$ & 1202 & $\mathrm{C}_{10} \mathrm{H}_{20} \mathrm{O}$ & 18.72 & RI, MS \\
\hline 2 & Undecanal & 1308 & $\mathrm{C}_{11} \mathrm{H}_{22} \mathrm{O}$ & 0.30 & RI, MS \\
\hline 3 & Dodecanal & 1413 & $\mathrm{C}_{12} \mathrm{H}_{24} \mathrm{O}$ & 54.25 & RI, MS \\
\hline 4 & Tetradecanal & 1614 & $\mathrm{C}_{14} \mathrm{H}_{28} \mathrm{O}$ & 1.99 & RI, MS \\
\hline \multirow[t]{3}{*}{5} & $\alpha$-Sinensal & 1757 & $\mathrm{C}_{15} \mathrm{H}_{22} \mathrm{O}$ & 0.17 & RI, MS \\
\hline & Total & & & 75.43 & \\
\hline & Alcohol & & & & \\
\hline 6 & $\overline{1-N o n a n o l}$ & 1169 & $\mathrm{C}_{9} \mathrm{H}_{18} \mathrm{O}$ & 0.06 & RI, MS \\
\hline 7 & Myrtenol & 1196 & $\mathrm{C}_{10} \mathrm{H}_{16} \mathrm{O}$ & $\operatorname{tr}^{\mathrm{e}}$ & RI, MS \\
\hline 8 & 1-Decanol & 1197 & $\mathrm{C}_{10} \mathrm{H}_{22} \mathrm{O}$ & $\operatorname{tr}^{\mathrm{e}}$ & RI, MS \\
\hline 9 & Geraniol & 1253 & $\mathrm{C}_{10} \mathrm{H}_{18} \mathrm{O}$ & 1.82 & RI, MS \\
\hline 10 & 1-Dodecanol & 1274 & $\mathrm{C}_{12} \mathrm{H}_{26} \mathrm{O}$ & 1.63 & RI, MS \\
\hline 11 & 1-Undecanol & 1370 & $\mathrm{C}_{11} \mathrm{H}_{24} \mathrm{O}$ & 0.36 & RI, MS \\
\hline 12 & Farnesol & 1544 & $\mathrm{C}_{15} \mathrm{H}_{26} \mathrm{O}$ & 0.40 & RI, MS \\
\hline 13 & Nerolidol & 1561 & $\mathrm{C}_{15} \mathrm{H}_{26} \mathrm{O}$ & 1.00 & RI, MS \\
\hline 14 & Globulol & 1585 & $\mathrm{C}_{15} \mathrm{H}_{26} \mathrm{O}$ & 0.17 & RI, MS \\
\hline 15 & $\alpha$-(Z)-Bergamotol & 1606 & $\mathrm{C}_{15} \mathrm{H}_{24} \mathrm{O}$ & 0.80 & RI, MS \\
\hline 16 & Pinocarveol & 1634 & $\mathrm{C}_{15} \mathrm{H}_{24} \mathrm{O}$ & 0.39 & RI, MS \\
\hline 17 & $\alpha$-Bisabolol & 1668 & $\mathrm{C}_{15} \mathrm{H}_{26} \mathrm{O}$ & 1.19 & RI, MS \\
\hline \multirow[t]{4}{*}{18} & Drimenol & 1941 & $\mathrm{C}_{15} \mathrm{H}_{26} \mathrm{O}$ & 0.25 & RI, MS \\
\hline & Total & & & 8.07 & \\
\hline & Terpenoid & & & & \\
\hline & Monoterpene & & & & \\
\hline \multirow[t]{3}{*}{19} & Bornyl acetate & 1285 & $\mathrm{C}_{12} \mathrm{H}_{20} \mathrm{O}_{2}$ & 0.91 & RI, MS \\
\hline & Total & & & 0.91 & \\
\hline & Sesquiterpene & & & & \\
\hline 20 & $\alpha$-Bergamotene & 1420 & $\mathrm{C}_{15} \mathrm{H}_{24}$ & 1.12 & RI, MS \\
\hline 21 & Seychellene & 1447 & $\mathrm{C}_{15} \mathrm{H}_{24}$ & 0.57 & RI, MS \\
\hline 22 & $\alpha$ - Caryophyllene & 1456 & $\mathrm{C}_{15} \mathrm{H}_{24}$ & 1.72 & RI, MS \\
\hline 23 & $\beta$-Farnesene & 1457 & $\mathrm{C}_{15} \mathrm{H}_{24}$ & 1.73 & RI, MS \\
\hline 24 & $\alpha$-Curcumene & 1483 & $\mathrm{C}_{15} \mathrm{H}_{24}$ & $\operatorname{tr}^{\mathrm{e}}$ & RI, MS \\
\hline 25 & $\beta$-Selinene & 1490 & $\mathrm{C}_{15} \mathrm{H}_{24}$ & 1.36 & RI, MS \\
\hline 26 & $\alpha$-Zingiberene & 1494 & $\mathrm{C}_{15} \mathrm{H}_{24}$ & 0.66 & RI, MS \\
\hline 27 & Valencene & 1496 & $\mathrm{C}_{15} \mathrm{H}_{24}$ & 0.47 & RI, MS \\
\hline 28 & Germacrene D & 1497 & $\mathrm{C}_{15} \mathrm{H}_{24}$ & 1.08 & RI, MS \\
\hline 29 & 4, 11-Selinadiene & 1498 & $\mathrm{C}_{15} \mathrm{H}_{24}$ & 0.18 & RI, MS \\
\hline 30 & $\beta$-Bisabolene & 1507 & $\mathrm{C}_{15} \mathrm{H}_{24}$ & 0.11 & RI, MS \\
\hline 31 & $\alpha$-Panasinsene & 1519 & $\mathrm{C}_{15} \mathrm{H}_{24}$ & 0.58 & RI, MS \\
\hline 32 & $\alpha$-Sesquiphellandrene & 1523 & $\mathrm{C}_{15} \mathrm{H}_{24}$ & 0.38 & RI, MS \\
\hline 33 & $\delta$ - Cadinene & 1539 & $\mathrm{C}_{15} \mathrm{H}_{24}$ & 1.05 & RI, MS \\
\hline 34 & $\alpha$-Humulene & 1555 & $\mathrm{C}_{15} \mathrm{H}_{24}$ & 0.17 & RI, MS \\
\hline 35 & $\beta$-Caryophyllene oxide & 1582 & $\mathrm{C}_{15} \mathrm{H}_{24} \mathrm{O}$ & 1.51 & RI, MS \\
\hline 36 & Alloaromadendrene & 1625 & $\mathrm{C}_{15} \mathrm{H}_{24}$ & 0.31 & RI, MS \\
\hline \multirow[t]{3}{*}{37} & Isocaryophyllene & 1737 & $\mathrm{C}_{15} \mathrm{H}_{24}$ & 0.20 & RI, MS \\
\hline & Total & & & 13.19 & \\
\hline & Acid & & & & \\
\hline 38 & $\overline{\text { n-Decanoid acid }}$ & 1373 & $\mathrm{C}_{10} \mathrm{H}_{20} \mathrm{O}_{2}$ & 0.38 & RI, MS \\
\hline \multirow[t]{2}{*}{39} & Dodecanoid acid & 1546 & $\mathrm{C}_{12} \mathrm{H}_{24} \mathrm{O}_{2}$ & 0.45 & RI, MS \\
\hline & Total & & & 0.83 & \\
\hline
\end{tabular}

MS column with homologous series of n-alkanes C8-C20 and C21-C40. ${ }^{\circ}$ Relative amount based on a percentage peak area. ${ }^{d} \mathrm{RI}$, based on retention index; MS, based on mass spectra matching. ${ }^{\mathrm{c}}$ tr $(<0.01 \%)$.

Table 2 Aroma extraction dilution analysis of $P$. minus leaf essential oil.

\begin{tabular}{|c|c|c|c|c|}
\hline Peak. & Compound & Odour description $^{\text {a }}$ & FD value $^{b}$ & FD-factor $\left(2^{\mathrm{n}}\right)$ \\
\hline 1 & 1-nonanal & Grassy, citrus & 512 & 9 \\
\hline 2 & 1-Decanol & Pungent, orange peel & 16 & 4 \\
\hline 3 & Decanal & Green, citrus-like & 1024 & 10 \\
\hline 4 & Bornyl acetate & Herb, balsamic & 128 & 7 \\
\hline 5 & Undecanal & Pungent, citrus & 256 & 8 \\
\hline 6 & Dodecanal & Pungent oily & 1024 & 10 \\
\hline 7 & $\alpha$-Bergamotene & Citrus & 1024 & 10 \\
\hline 8 & $\beta$-Farnesene & Floral, green plant & 256 & 8 \\
\hline 9 & $\beta$-Selinene & Floral & 128 & 7 \\
\hline 10 & Germacrene D & Woody, spice & 64 & 6 \\
\hline 11 & $\beta$-Bisabolene & Spice, balsamic & 256 & 8 \\
\hline 12 & $\delta$-Cadinene & Mild, woody & 128 & 7 \\
\hline 13 & Farnesol & Woody, herb & 512 & 9 \\
\hline 14 & Nerolidol & Woody, spicy, floral & 256 & 8 \\
\hline 15 & Caryophyllene oxide & Woody, spice & 128 & 7 \\
\hline 16 & Tetradecanal & Woody, floral & 32 & 5 \\
\hline 17 & Alloaromadendrene & Woody & 32 & 5 \\
\hline 18 & Drimenol & Woody & 16 & 4 \\
\hline
\end{tabular}




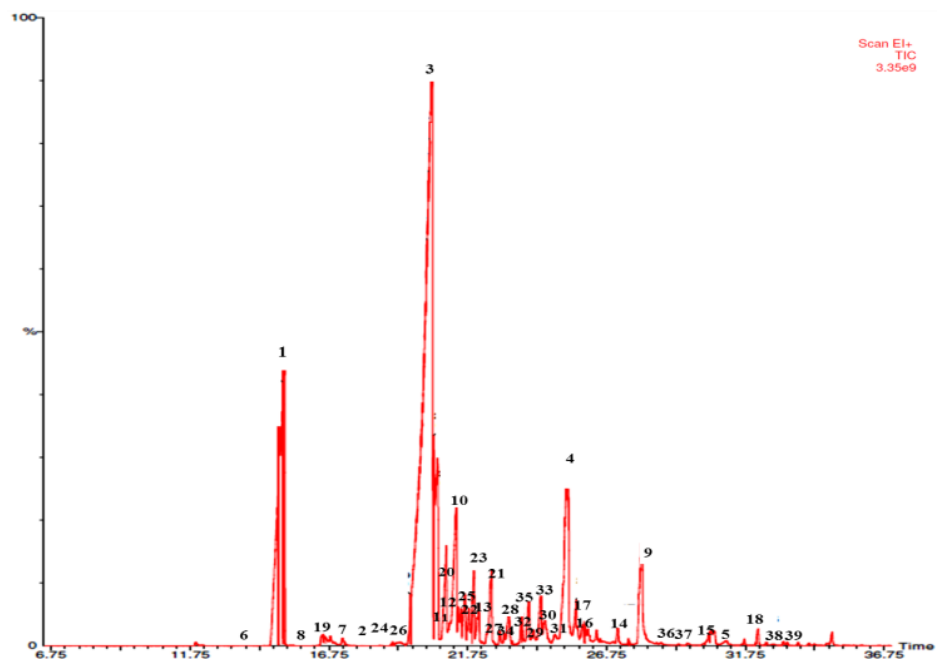

Fig 1. -MS/O chromatogram of P. minus essential oil.

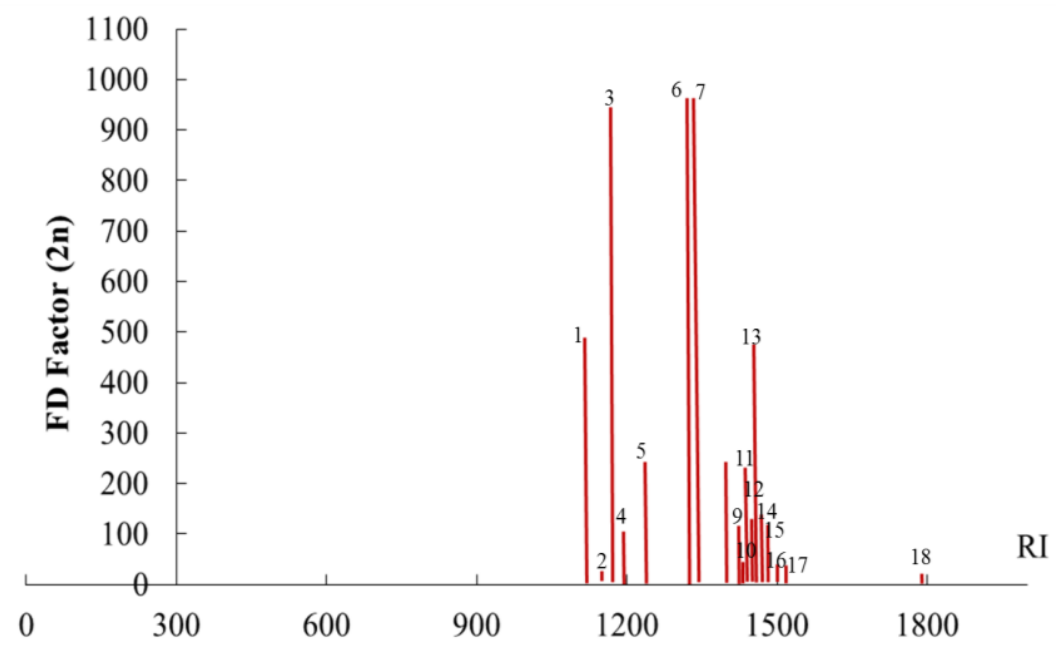

Fig 2. GC-MS/O aromagram P. minus essential oil generated using AEDA analysis. Numbers corresponds to the aroma described and indicated in Table 2

high FD factors of these compounds may result from the high concentrations of the compounds in the essential oil.

The sesquiterpenes group was the largest class of odouractive compounds in the oil sample. $\alpha$-Bergamotene (citrus), $\beta$-farnesene (floral, green plant), $\beta$-selinene (floral), germacrene D (woody, spice), $\beta$-bisabolene (spice, balsamic), $\delta$-cadinene (mild, woody), caryophyllene oxide (woody, spicy) and alloaromadendrene (woody) were detected as aroma-active terpene compounds in the kesum oil extracts. Among the terpenes detected by GC-MS/O, the most potent aroma-active terpenes were $\alpha$-bergamotene and $\beta$-bisabolene. The FD factors of these compounds were 1024 and 256, respectively. Most of the compounds from the terpene groups found in the $P$. minus oil had a pleasant odour. Alcohols contributed to the woody, herbal, floral and spicy smell of the kesum oil. These included farnesol (woody, herb), nerolidol (woody, spicy, floral) and drimenol (woody), in descending order of FD value.

The overall aroma of $P$. minus essential oil depends on the complex mixture of aroma-active compounds. Additionally, variation in the composition of the essential oil had a significant impact on the sensory odour characteristics. It can be concluded that aroma is a combination of the major volatile compounds in the essential oil with high intensity characteristic odour notes perceived by the panellists.

\section{Materials and Methods}

\section{Chemicals and reagents}

All chemicals used were of analytical grade and were purchased from Merck (Whitehouse Station, New Jersey, USA) unless stated otherwise. Anhydrous sodium sulphate was bought from Fisher Scientific International Laboratory (Hampton, New Hampshire, UK). Ultrapure water was generated by a Milli-Q purification system (Millipore, Molshem, France).

\section{Plant materials}

Leaves from $P$. minus were harvested in the morning between 8 and 9 am from the INBIOSIS experimental plot of the Universiti Kebangsaan Malaysia (UKM) in January 2013. The plant samples were originally collected from Ulu Yam, 
Selangor, Malaysia (UY; $3^{\circ} 16^{\prime} 14.63$ " N, 101 $1^{\circ} 41$ ' 11.32 " E). The plant was identified by a taxonomist and further confirmed using ITS sequences (Bunawan et al., 2011). Voucher specimens were deposited at the UKM herbarium.

\section{Extraction of essential oil}

Fresh whole leaves $(250 \mathrm{~g})$ were subjected to LikensNickerson simultaneous distillation extraction (Márquez et al., 2013) for 8 hours in a Clevenger-type apparatus on the day of collection. The essential oil was separated from water as an upper phase, without any added extraction solvent and was then dried over anhydrous sodium sulphate and diluted in n-hexane for the GC-MS/O analysis.

\section{Gas chromatography-mass spectrometry analysis}

GC-MS analysis was performed with a Perkin Elmer Clarus 600 chromatograph. The GC was equipped with a capillary column (Elite-5 $30 \mathrm{~m} \times 0.25 \mathrm{~mm}$, film thickness $0.25 \mu \mathrm{m}$ ). The initial oven temperature was programmed to change from 60 to $260^{\circ} \mathrm{C}$ at a rate of $5^{\circ} \mathrm{C} / \mathrm{min}$ and was held at $260^{\circ} \mathrm{C}$ for $5 \mathrm{~min}$. The injections of an ion source EI were adjusted to $270^{\circ} \mathrm{C}$ and $280^{\circ} \mathrm{C}$, respectively. The helium carrier gas was set to a flow rate of $1 \mathrm{~mL} / \mathrm{min}$. The detector interface temperature was set to $280^{\circ} \mathrm{C}$, with the actual temperature in the MS source reaching approximately $230^{\circ} \mathrm{C}$, and the ionisation energy was $70 \mathrm{eV}$. A $1 \mu \mathrm{L}$ volume of the dilution was injected at a split ratio of 1:50. The acquisition mass range was 39-600 amu. The percent composition was computed from the GC-MS peak areas on an Elite-5 MS column without applying correction factors.

\section{Identification of compounds and statistical analysis}

Compound identification was carried out using the NIST (version 2.0) library data and Wiley Registry $8^{\text {th }}$ Edition database of mass spectra and literature data. The information on volatiles was extracted based on the name of the compounds with the match and reverse match values below 800 filtered. To quantify the relative proportions of constituents, we used the calculation method based on peak area normalisation according to Hai-Peng et al., Hai-Peng et al. (2012).

Relative content $(\%=$ single constituent area $\div$ total area $\times$ $100 \%)$.

\section{Calculation of the retention indices $(R I)$}

To obtain the Kováts indices, n-alkane standard solutions of C8-C20 (mixture No. 04070) and C21-C40 (mixture No. 04071) from Fluka Chemical (Sigma-Aldrich) were used. The retention indices of the essential oil compounds were determined according to the standard method for Kováts indices to support the identification of the compounds. All values are averages from at least three experiments with three biological and three technical replicates.

\section{Gas chromatography-mass spectrometry/olfactometry analysis}

GC-MS/O analysis was carried out using a Perkin Elmer Clarus 600 chromatograph instrument equipped with a Clarus 600T mass spectrometer and an ODO II sniffing port (Olfactory Detector, SGE Analytical Science, Melbourne, Australia). The initial oven temperature was programmed to change from 60 to $260^{\circ} \mathrm{C}$ at a rate of $4^{\circ} \mathrm{C} / \mathrm{min}$ and was then held at $260^{\circ} \mathrm{C}$ for $5 \mathrm{~min}$. The injections of an ion source EI were adjusted to $270^{\circ} \mathrm{C}$ and $280^{\circ} \mathrm{C}$, respectively. The helium carrier gas was set to a flow rate of $1 \mathrm{~mL} / \mathrm{min}$. For the odour profiling, $2 \mu \mathrm{L}$ of the extract was injected. The column outlet split into two lines (ratio of approximately 1:1) leading to the detector and a sniffing port (olfactory detector outlet). In the sniffing port, the effluent was mixed with humidified air. The GC-MS/O separated the complex mixtures into individual components. The separated compounds were then split and simultaneously directed to a mass spectrometer coupled to an olfactory port or "sniffer". The olfactory port allows the panellists to assess the components through the perception of odour. Panellists repeated the analysis 3 times on each sample. Simultaneous analysis by the MS enables the odorous molecules to be identified using chemical library software NIST (version 2.0) and the Wiley Registry 8th Edition database.

\section{Aroma extraction dilution analysis}

To collect and process data from the GC-MS/O, AEDA was performed based on stepwise dilution. The essential oil was stepwise diluted with n-hexane $(1: 2,1: 4,1: 8,1: 16,1: 32$, $1: 64,1: 128,1: 256,1: 512,1: 1024)(\mathrm{v} / \mathrm{v})$ according to Kang and Baek, (2014). The highest sample dilution was assigned an FD factor of one. Aliquots were then analysed by GCMS/O as described above. Four panellists independently analysed each sample in triplicate for the detection of aromaactive compounds. The panellists recorded the retention time along with the descriptor for each odour. The procedure was performed until no odourant was perceivable. All the descriptions of the odour were according to flavournet.org (http://www.flavournet.org/flavournet.html).

\section{Conclusion}

This study identified the aroma-active compounds that are responsible for the overall aroma of $P$. minus essential oil. In summary, 39 major volatile compounds were identified in the essential oil of $P$. minus by GC-MS analysis, and 18 potent odourants were identified by GC-MS/O combined with AEDA analysis. The main aroma-active compounds responsible for the unique fragrance in $P$. minus essential oil are decanal, dodecanal, $\alpha$-bergamotene, $\delta$-cadinene, $\beta$ farnesene, germacrene $D$, and farnesol. Some of these compounds were not reported in previous studies. This study provides useful information on the aroma profile of volatiles and the sensory quality of $P$. minus essential oil. This study also demonstrated that the $P$. minus characteristic odour arises from the perception of a mixture of volatiles. Further research is needed to understand what constitutes a desirable combination of active aromatic compounds. To our knowledge, this is the first report using combined GC-MS/O and AEDA to identify compounds that contribute significantly to the characteristic aroma of $P$. minus. We have demonstrated an integrated approach of GC-MS and GC-O with AEDA for the identification of aroma-active compounds. This method can be applied to other commercially important herbal plants with potential in aromatherapy.

\section{Acknowledgements}

The authors thank Kamarul Azlan Azizan and Syahmi Afiq Mustaza for their technical assistance and the reviewers for their constructive comments. This work was funded by Research University Grants from Universiti Kebangsaan 
Malaysia (UKM-GUP-2013-028 and DLP 2013-024) awarded to Syarul Nataqain Baharum. We also acknowledge the Centre for Research and Instrumentation Management (CRIM), UKM for a Research Instrumentation Development Grant 2010 (PIP-CRIM)

\section{References}

Acree TE (1997) Peer reviewed: GC/Olfactometry GC with a sense of smell. Anal Chem. 69(5):170A-175A.

Ahmad R, Baharum SN, Bunawan H, Lee M, Noor NM, Rohani ER, Ilias N, Zin NM (2014)

Volatile profiling of aromatic traditional medicinal plant, Polygonum minus in different

tissues and its biological activities. Molecules 19(11):922019242.

Baharum SN, Bunawan H, Ghani MA, Mustapha WAW, Noor NM (2010) Analysis of the chemical composition of the essential oil of Polygonum minus Huds. using twodimensional gas chromatography-time-of-flight mass spectrometry (GC-TOF-MS). Molecules 15(100):70067015.

Bondia-Pons I, Savolainen O, Törrönen R, Martinez JA, Poutanen K, Hanhineva K (2014) Metabolic profiling of Goji berry extracts for discrimination of geographical origin by non-targeted liquid chromatography coupled to quadrupole time-of-flight mass spectrometry. Food Res Int. 63:132-138

Brattoli M, Cisternino E, Dambruoso PR, de Gennaro G, Giungato P, Mazzone A, Palmisani J, Tutino M (2013) Gas chromatography analysis with olfactometric detection (GC$\mathrm{O})$ as a useful methodology for chemical characterization of odorous compounds. Sensors 13(12):16759-16800.

Brunschwig C, Senger-Emonot P, Aubanel M, Pierrat A, George G, Rochard S, Raharivelomanana P (2012) Odoractive compounds of Tahitian vanilla flavour. Food Res Int. 46:148-157.

Bunawan H, Choong C, Md-Zain B, Baharum SN, Noor NM (2011) Molecular systematics of Polygonum minus Huds. based on ITS sequences. Int J Mol Sci. 12(11):7626-7634.

Delahunty C, Eyres G, Dufour JP (2006) Gas chromatography-olfactometry. J Sep Sci. 29(14):210-2125.

Figueiredo AC, Barroso JG, Pedro LG, Scheffer JJC (2008) Factors affecting secondary metabolite production in plants: volatile components and essential oils. Flavour Frag J. 23(4):213-226.

George A, Chinnappan S, Chintamaneni M, Kotak CV, Choudhary Y, Kueper T, Radhakrishnan A (2014) Antiinflammatory effects of Polygonum minus (Huds) extract (LineminusTM) in vitro enzyme assays and carrageenaninduced paw oedema. BMC Complem Altern $\mathrm{M}$. 14(1):355- 362 .
Goodner KL, Mahattanataweea K, Plotto A, Sotomayor JA, Jord'a JM (2006) Aromatic profiles of Thymus hyemalis and Spanish T. vulgaris essential oils by $\mathrm{GC}-\mathrm{MS} / \mathrm{GC}-\mathrm{O}$. Ind Crop Prod. 24:264-268.

Hai-Peng L, Qiu-Sheng Z, Lin Z, Wang L, Jun-Feng T, Guo L (2012). Aroma characterisation of Puerh tea using headspace-solid phase microextraction combined with GC/MS and GC-olfactometry. Food Chem. 130:1074 1081.

Haris HH, Ming YK, Perin F, Blanche C, Jinapong N (2014) Split-face placebo controlled evaluation of the in vivo antiageing efficacy of lineminus ${ }^{\mathrm{TM}}$ cream (Polygonum minus extract) in healthy Asian skin type female subjects. Asian J Pharm Clin Res. 7:7-13.

Hunter M (1996) Australian kesom oil- a new essential oil for the flavour and fragrance industry. Agro Food Ind Hi Tec. 7:26-28.

Jiang J (2005) Volatile composition of the laksa plant (Polygonum hydropiper L.) a potential source of green tea aroma compounds. Flavour Frag J. 20:455-459.

Kang K, Baek H (2014) Aroma quality assessment of Korean fermented red pepper paste (gochujang) by aroma extract dilution analysis and headspace solid-phase microextraction - gas chromatography-olfactometry. Food Chem. 145:488 - 495 .

Kesen S, Kelebek H, Selli S (2014) Characterization of potent odorant compounds in Turkish olive oil by GC-MSolfactometric techniques. Int J Food Stud. 3:248-257.

Lo YCM, Koziel JA, Cai L, Hoff SJ, Jenks WS, Xin H (2008) Simultaneous chemical and

sensory characterization of volatile organic compounds and semi-volatile organic compounds emitted from swine manure using solid phase microextraction and multidimensional gas chromatography-mass spectrometryolfactometry. J Environ Qual. 37:521-534.

Márquez V, Martínez N, Guerra M, Fariña L, Boido E, Dellacassa E (2013) Characterization

of aroma-impact compounds in yerba mate (Ilex paraguariensis) using GC-olfactometry and GC-MS. Food Res Int. 53:808-815.

Miyazawa M, Nomura M, Marumoto S, Mori K (2013) Characteristic odor components of essential oil from Scutellaria laetoviolacea. J Oleo Sc. 62:51-56.

Starkenmann C, Luca L, Niclass Y (2006) Comparison of volatile constituents of Persicaria odorata (Lour.) Soják (Polygonum odoratum Lour.) and Persicaria hydropiper L. Spach (Polygonum hydropiper L.). J Agr Food Chem. 54:3067-3071.

Van Ruth, SM (2001) Methods for gas chromatography olfactometry: A review. Biomol Eng. 17(4-5):121-128.

Wan Hassan WE (2007) Healing herbs of Malaysia. Federal Land Development Authority (FELDA). Kuala Lumpur, Malaysia.

Zakaria M, Mohd MA (2010) Traditional Malay medicinal plants. Institut Terjemahan Negara (ITNM). Malaysia. Kuala Lumpur, Malaysia. 